\title{
Liver Cirrhosis and Kidney
}

\author{
Alexander L. Gerbes \\ Medizinische Klinik II, Klinikum der Universität München, München, Germany
}

\section{Key Words}

Acute kidney injury - Acute-on-chronic liver failure .

Ascites · Beta-blockers · Hepatorenal syndrome

\begin{abstract}
Background: Renal failure in cirrhosis may be due to various causes. While treatment for patients with ascites and hepatorenal syndrome is established, recent attention has been focused on acute kidney injury (AKI) in cirrhosis. Key Messages: The reduction of centrally effective blood volume is the key to the pathophysiology of renal failure and ascites formation in cirrhosis. Therefore, albumin infusion following large volume paracentesis is recommended by all guidelines. In selected patients, transjugular intrahepatic portosystemic shunt provides good control of ascites and improves survival. The role of non-selective beta-blockers in patients with cirrhosis and ascites is being controversially discussed. AKI in cirrhosis has been redefined and has prognostic importance. Conclusions: The role of kidney function in patients with liver cirrhosis is receiving increasing attention. In particular, the use of beta-blockers and novel definitions of AKI seem to be of clinical relevance.
\end{abstract}

(c) 2016 S. Karger AG, Basel

In patients with cirrhosis, renal failure can have various causes such as parenchymal nephropathy, hypovolemia, infection and hepatorenal syndrome. Among those, hepatorenal syndrome has the worst and parenchymal nephropathy - the relatively best prognosis. Prerenal failure and hepatorenal syndrome are among the most common causes of renal insufficiency in liver disease. In these patients, portal hypertension and splanchnic vasodilatation causes a shift in blood volume away from the central circulation. This reduction of centrally effective blood volume induces a stimulation of counter-regulatory mechanisms such as activation of renin-aldosterone and of the sympathetic nervous system. This results in renal sodium retention, functional renal failure and ascites formation. Therefore, marked, fast decreases of plasma volume must be avoided in the treatment of ascites [1].

Large volume paracentesis can induce circulatory dysfunction, resulting in renal failure. Albumin infusion following paracentesis has been impressively shown to reduce circulatory dysfunction and to improve survival [2]. Therefore, most guidelines recommend albumin infusion following large volume paracentesis in patients with cirrhosis. For patients with massive ascites, transjugular intrahepatic portosystemic shunt (TIPS) provides good control of ascites and reduces the number of paracentesis. Moreover, TIPS improves survival in these patients. For these beneficial effects, selection of suitable patients is crucial. Therefore, patients with serum bilirubin $>5 \mathrm{mg} /$ $\mathrm{dl}$ or pre-existing hepatic encephalopathy should not be TIPS candidates [3].

Recently, the role of beta-blockers in patients with cirrhosis and ascites has been controversially discussed.

\section{KARGER}

E-Mail karger@karger.com

www.karger.com/ddi (c) 2016 S. Karger AG, Basel

0257-2753/16/0344-0387\$39.50/0
Alexander L. Gerbes

Medizinische Klinik II, Klinikum der Universität

München - Grosshadern, Marchioninistrasse 15

DE-81377 München (Germany)

E-Mail gerbes@med.uni-muenchen.de 
Fig. 1. NSBB improve survival of patients with ascites on the liver transplantation waiting list. The figure shows the cumulative incidence of death over time (adapted from [7]).

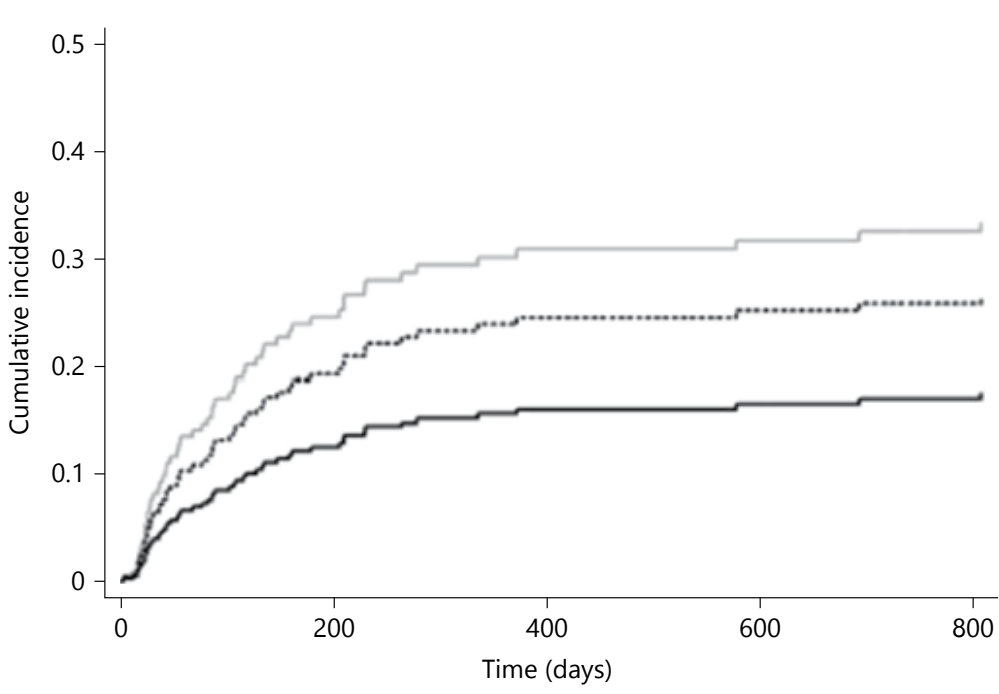

Number of patients at risk

Non-NSBB 104

Carvedilol 26

Propanolol $\quad 78$
While beta-blockers reduce portal pressure and therefore the risk of variceal bleeding, they also decrease cardiac output and may impair renal perfusion. A retrospective study reported an increase of mortality risk in patients with refractory ascites receiving beta-blockers [4]. This was not confirmed by another report [5] in which the patients received a lower mean daily propranolol dose than in the afore-mentioned study (49 vs. 113 $\mathrm{mg} /$ day). Untoward effects of beta-blockers may indeed be mediated by their effect on mean arterial pressure. Patients with spontaneous bacterial peritonitis may be particularly prone to develop hypotension when receiving beta-blockers. This effect has been shown to be linked with survival: while patients with spontaneous bacterial peritonitis had an increased mortality risk, this was not the case in patients undergoing paracentesis without spontaneous bacterial peritonitis [6]. A recent prospective study has shown that non-selective betablockers (NSBB) improve survival probability of patients with ascites on the transplant waiting list [7]. Interestingly, patients receiving Carvedilol had less benefit than patients receiving propranolol (fig. 1). This may be due to a more marked effect of Carvedilol on systemic arterial pressure. Altogether, the use of beta-blockers and particularly the dosage should be judiciously estimated, particularly in patients with spontaneous bacte-

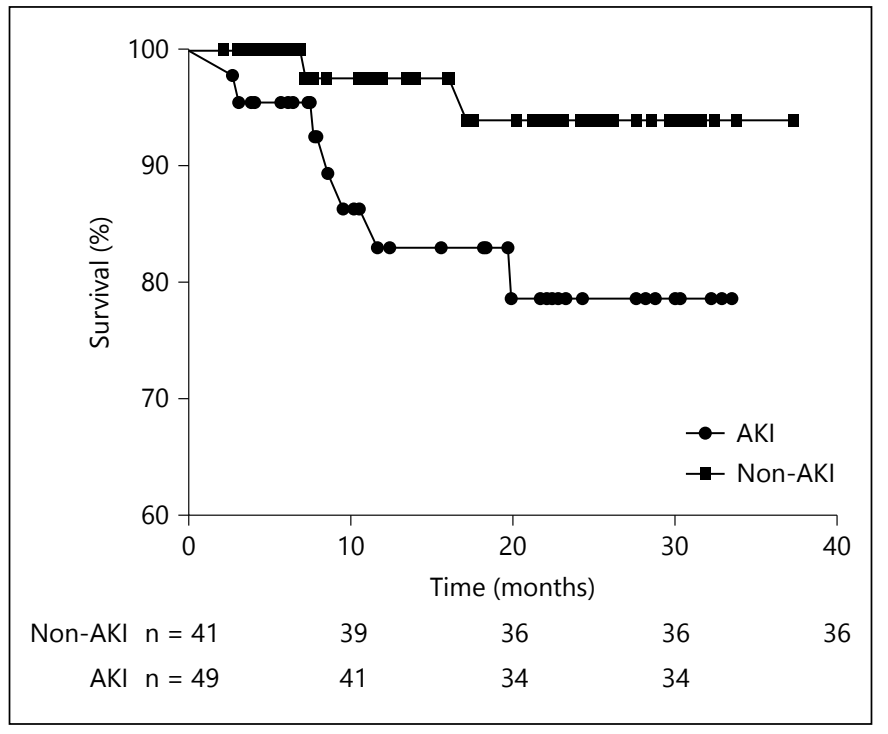

Fig. 2. Survival probability is significantly reduced $(\mathrm{p}=0.049)$ in patients with AKI (adapted from [13]).

rial peritonitis [8] or patients with low systolic blood pressure.

Hepatorenal syndrome, particularly type I has a detrimental prognosis [9]. Recent studies have shown that administration of terlipressin plus albumin can improve re- 

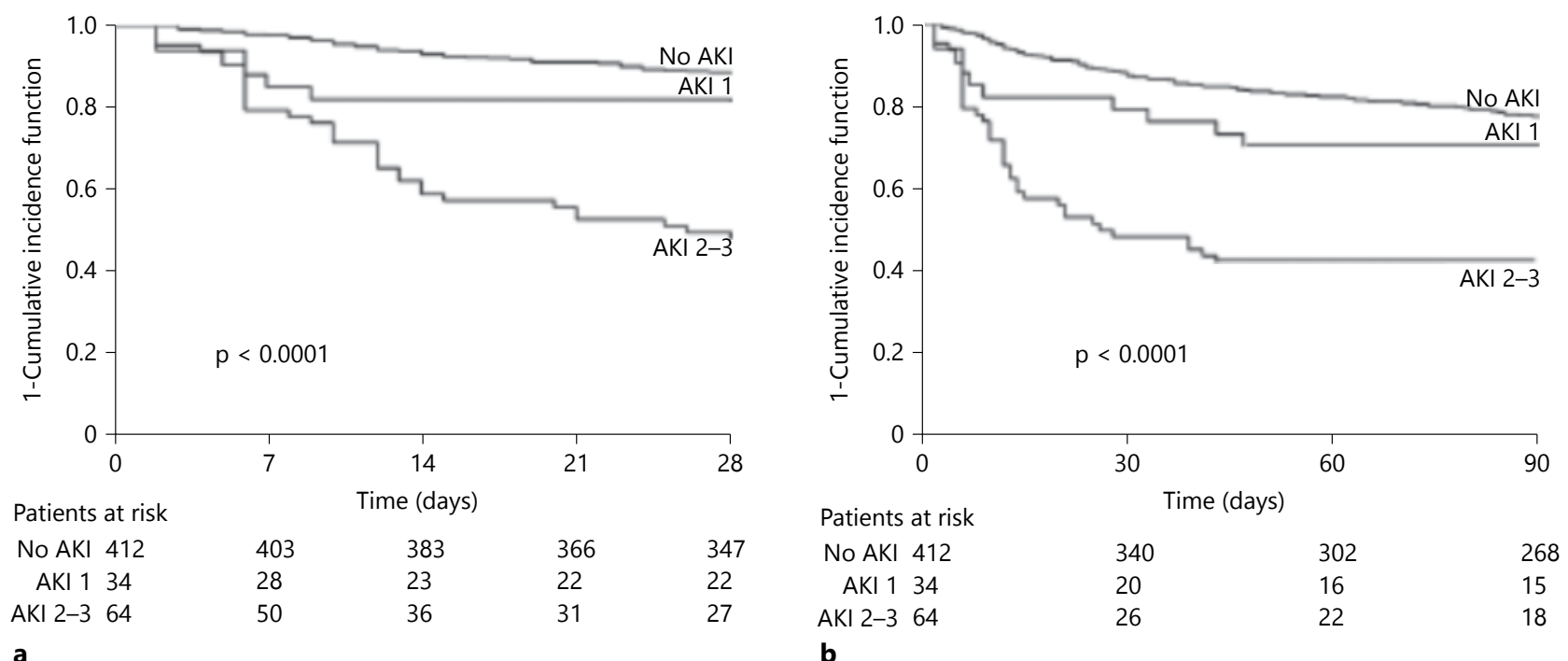

a

Fig. 3. Probability of survival in patients with acute-on-chronic liver failure is affected by AKI. Patients with AKI stages $2-3$ exhibit a significantly lower probability of 28 days (a) and 90 days (b) survival, respectively (adapted from [15]).

Table 1. New definitions for the diagnosis and management of AKI in patients with cirrhosis according to [14]

\begin{tabular}{|c|c|}
\hline Subject & Definition \\
\hline Definition of AKI & $\begin{array}{l}\text { Increase in } \mathrm{sCr} \geq 0.3 \mathrm{mg} / \mathrm{dl}(\geq 26.5 \mathrm{mmol} / \mathrm{l}) \text { within } 48 \mathrm{~h} \text {; or a percentage increase } \mathrm{sCr} \geq 50 \% \text { from baseline } \\
\text { which is known, or presumed, to have occurred within the prior } 7 \text { days }\end{array}$ \\
\hline Staging of AKI & $\begin{array}{l}\text { Stage 1: increase in } \mathrm{sCr} \geq 0.3 \mathrm{mg} / \mathrm{dl}(26.5 \mathrm{mmol} / \mathrm{l}) \text { or an increase in } \mathrm{sCr} \geq 1.5-2 \text {-fold from baseline } \\
\text { Stage } 2: \text { increase in } \mathrm{sCr}>2-3 \text {-fold from baseline } \\
\text { Stage } 3: \text { increase of } \mathrm{sCr}>3 \text {-fold from baseline or } \mathrm{sCr} \geq 4.0 \mathrm{mg} / \mathrm{dl}(353.6 \mathrm{mmol} / \mathrm{l}) \text { with an acute increase } \\
\geq 0.3 \mathrm{mg} / \mathrm{dl}(26.5 \mathrm{~mol} / \mathrm{l}) \text { or initiation of renal replacement therapy }\end{array}$ \\
\hline
\end{tabular}

nal function in patients with hepatorenal syndrome type 1 and can reduce short-term mortality [10]. However, time to response is rather long and the traditional definition of hepatorenal syndrome has been questioned as a prerequisite for starting innovative treatments. Recently, a proposal to broaden the diagnosis of renal dysfunction in cirrhosis has been put forward [11]. It includes cases of acute and chronic renal failure not meeting the diagnostic criteria of hepatorenal syndrome types 1 and 2, respectively. Rather acute kidney injury (AKI), similarly as in patients without cirrhosis should include all causes of acute deterioration of renal function as indicated by an increase of serum creatinine by $>50 \%$ from baseline or a rise of $\geq 0.3 \mathrm{mg} / \mathrm{dl}$ within few days. Such renal dysfunction is a defining feature of acute-on-chronic liver failure [12].

Liver Cirrhosis and Kidney
Interestingly, patients characterized by such minor renal dysfunction over time exhibit a continuous increase of serum creatinine and a decrease of mean arterial pressure [13]. Consequently, mortality risk has been shown increased in these patients (fig. 2). Based on such observations, the International Club of Ascites has established new definitions for the diagnosis and management of AKI in patients with cirrhosis [14] (table 1). Indeed, the stage of AKI is a predictor of survival in these patients [15] (fig. 3).

\section{Disclosure Statement}

The author declares no conflict of interest. 


\section{References}

1 Gerbes AL: The patient with refractory ascites. Best Pract Res Clin Gastroenterol 2007; 21:551-560.

2 Bernardi M, Caraceni P, Navickis RJ, Wilkes MM: Albumin infusion in patients undergoing large-volume paracentesis: a meta-analysis of randomized trials. Hepatology 2012;55: 1172-1181.

3 Rössle M, Gerbes AL: TIPS for the treatment of refractory ascites, hepatorenal syndrome and hepatic hydrothorax: a critical update. Gut 2010;59:988-1000.

4 Sersté T, Melot C, Francoz C, Durand F, Rautou PE, Valla D, Moreau R, Lebrec D: Deleterious effects of beta-blockers on survival in patients with cirrhosis and refractory ascites. Hepatology 2010;52:1017-1022.

5 Robins A, Bowden A, Watson W, Smith F, Gelson W, Griffiths W: Beta-blockers in cirrhosis patients with refractory ascites. Hepatology 2014;59:2054-2055.

6 Mandorfer M, Bota S, Schwabl P, Bucsics T, Pfisterer N, Kruzik M, Hagmann M, Blacky A, Ferlitsch A, Sieghart W, Trauner M, Peck-Ra- dosavljevic M, Reiberger T: Nonselective $\beta$ blockers increase risk for hepatorenal syndrome and death in patients with cirrhosis and spontaneous bacterial peritonitis. Gastroenterology 2014;146:1680-1690.

7 Leithead JA, Rajoriya N, Tehami N, Hodson J, Gunson BK, Tripathi D, Ferguson JW: Nonselective $\beta$-blockers are associated with improved survival in patients with ascites listed for liver transplantation. Gut 2015;64:1111-1119.

8 Wiest R, Krag A, Gerbes A: Spontaneous bacterial peritonitis: recent guidelines and beyond. Gut 2012;61:297-310.

9 Arroyo V, Ginès P, Gerbes AL, et al: Definition and diagnostic criteria of refractory ascites and hepatorenal syndrome in cirrhosis. International ascites club. Hepatology 1996; 23:164-176.

10 Salerno F, Gerbes A, Ginès P, Wong F, Arroyo $\mathrm{V}$ : Diagnosis, prevention and treatment of hepatorenal syndrome in cirrhosis. Gut 2007; 56:1310-1318.

11 Wong F, Nadim MK, Kellum JA, et al: Working party proposal for a revised classification system of renal dysfunction in patients with cirrhosis. Gut 2011;60:702-709.

12 Moreau R, Jalan R, Gines P, et al: Acute-onchronic liver failure is a distinct syndrome that develops in patients with acute decompensation of cirrhosis. Gastroenterology 2013;144:1426-1437.

13 Tsien CD, Rabie R, Wong F: Acute kidney injury in decompensated cirrhosis. Gut 2013; 62:131-137.

14 Angeli $\mathrm{P}$, Ginès $\mathrm{P}$, Wong $\mathrm{F}$, et al: Diagnosis and management of acute kidney injury in patients with cirrhosis: revised consensus recommendations of the International Club of Ascites. Gut 2015;64:531-537.

15 Angeli P, Rodríguez E, Piano S, Ariza X, Morando $\mathrm{F}$, Solà $\mathrm{E}$, Romano $\mathrm{A}$, García $\mathrm{E}$, Pavesi M, Risso A, Gerbes A, Willars C, Bernardi M, Arroyo V, Ginès P; CANONIC Study Investigators of EASL-CLIF Consortium: Acute kidney injury and acute-on-chronic liver failure classifications in prognosis assessment of patients with acute decompensation of cirrhosis. Gut 2015;64:1616-1622. 